\title{
Host Specificity of Phytophthora infestans on Tomato and Potato in Ecuador
}

\author{
P. J. Oyarzun, A. Pozo, M. E. Ordoñez, K. Doucett, and G. A. Forbes
}

First, second, third, and fifth authors: International Potato Center (CIP), P. O. Box 17-21-1977, Quito, Ecuador; and fourth author: Department of Plant Pathology, 334 Plant Science, Cornell University, Ithaca, NY 14853.

Accepted for publication 8 December 1997.

\begin{abstract}
Oyarzun, P. J., Pozo, A., Ordoñez, M. E., Doucett, K., and Forbes, G. A. 1998. Host specificity of Phytophthora infestans on tomato and potato in Ecuador. Phytopathology 88:265-271.

Sixty Ecuadorian isolates of Phytophthora infestans from potato and 60 isolates from tomato were compared for dilocus allozyme genotype, mitochondrial DNA haplotype, mating type, and specific virulence on 11 potato R-gene differential plants and four tomato cultivars, two of which contained different $\mathrm{Ph}$ genes. Restriction fragment length polymorphism (RFLP) fingerprints of subsamples of isolates from each host were compared by using RG57 as the probe. All potato isolates had the allozyme genotype, haplotype, and mating type of the clonal lineage EC-1, which had been previously described in Ecuador. With the same markers, only one isolate from tomato was classified as EC-1; all others belonged

to the globally distributed US-1 clonal lineage. RFLP fingerprints of isolate subsets corroborated this clonal lineage classification. Specific virulence on potato differentials was broadest among potato isolates, while specific virulence on tomato cultivars was broadest among tomato isolates. Some tomato isolates infected all tomato differentials but no potato differentials, indicating that specific virulence for the two hosts is probably controlled by different avirulence genes in $P$. infestans. In two separate experiments, the diameters of lesions caused by nine isolates from potato and 10 from tomato were compared on three tomato and three potato cultivars. All isolates produced larger lesions on the host from which they were isolated. No isolates were found that were highly aggressive on both tomato and potato. We conclude that there are two different populations of $P$. infestans in Ecuador and that they are separated by host.
\end{abstract}

The earliest reports on tomato late blight $(6,22,24,27)$ do not mention host specificity, and Berg (2) concluded that these early observers "believed that this fungus passed readily from potatoes to tomatoes." Specificity was subsequently described in a series of articles published during the first half of the twentieth century $(2,9,23,31)$. At that time, there were no markers available to establish genetic similarity, and therefore these conclusions were based primarily on observations of epidemics in the field or crossinoculations in the laboratory.

The development of unambiguous genetic markers enabled researchers to characterize populations of Phytophthora infestans (Mont.) deBary on both hosts, but results have been inconsistent in different geographic regions. Many isolates attacking tomato and potato in some regions of the Netherlands (8) and in North America $(15,20)$ could not be distinguished by restriction fragment length polymorphism (RFLP) fingerprint, dilocus allozyme genotype, or mating type. Furthermore, many isolates collected from tomato in North America were highly aggressive on potato in a detached-leaf assay (20). In contrast, the same genetic markers have shown that distinct genotypes are associated with each host in Brazil (4), northwestern Mexico (14), the Philippines (18), and one region of the Netherlands (8).

Studying the population of $P$. infestans in North America, Legard et al. (20) concluded that pathogenic aggressiveness on tomato evolved from within the potato-aggressive populations. All tomato-aggressive genotypes were still aggressive on potato, so aggressiveness on tomato was not associated with any measurable loss in aggressiveness on potato. However, this model of evolu-

Corresponding author: G. A. Forbes; E-mail address: forbes@cip.org.ec

Publication no. P-1998-0127-02R

(C) 1998 The American Phytopathological Society tion toward aggressiveness on tomato is not universally accepted. Turkensteen (29) argued that if genotypes of $P$. infestans were able to acquire equal aggressiveness on both hosts, they would rapidly replace those that are aggressive on only one host. Following this line of logic, one would not expect to see separate genotypes associated with each host, which, as noted above, is the case in several countries.

Both tomato and potato have major genes that confer complete or very high levels of resistance to $P$. infestans. They have been designated $\mathrm{R}$ genes in potato (3) and $\mathrm{Ph}$ genes in tomato (29). Specific incompatibility caused by major genes for resistance and corresponding avirulence genes in the pathogen have been studied in association with host resistance $(16,30)$, but the role of these major genes in host specificity has not been examined.

Host specificity has major consequences for disease management. For example, Legard et al. (20) concluded that potato farmers must initiate spraying if nearby tomato fields become infected. In a more general sense, if the same genotype of $P$. infestans can infect both hosts with equal aggressiveness, then integrated pest management efforts for both tomato and potato must be coordinated. If, however, genotypes from one host lack pathogenic aggressiveness on the other, farmers and integrated pest management specialists need not be concerned by epidemics on nearby alternative hosts.

In Ecuador, both tomato and potato are cultivated year round for commercial and subsistence purposes. Late blight of tomato and potato can occur at any stage of plant growth after emergence because of the continuous presence of inoculum and favorable conditions. Potato and tomato are not generally grown in immediately adjacent areas, but production zones for the two crops can be within kilometers of each other and are sometimes contiguous. Occasionally, we have seen potato and tomato grown on the same farm and on rare occasions in the same field. 
This study was initiated to address two questions about the host specificity of $P$. infestans in Ecuador: (i) whether or not tomatoes and potatoes are attacked by the same population of $P$. infestans; and (ii) whether or not specific virulence plays a role in determining host specificity in this system.

\section{MATERIALS AND METHODS}

Isolates. Forty-one potato isolates, which had been collected in 1993 as part of another study (7), were used. Nineteen additional isolates were collected from potato plants from the center, northcentral, and northern parts of Ecuador between November 1994 and February 1995 (Table 1). In the center of the country, potato isolates were collected near the towns of Riobamba and Pallatanga. In the north-central part, they were collected around the capital city of Quito and near the town of Alchichipa. In the north, isolates were collected near the town of San Gabriel.

Tomato isolates were collected principally near the towns of Pallatanga in central Ecuador, Alchichipa in north-central Ecuador, and in the valley of El Chota in northern Ecuador (Table 1). Pallatanga is approximately $50 \mathrm{~km}$ from potato-production areas near the city of Riobamba, Alchichipa is approximately $50 \mathrm{~km}$ from potato production near Quito, and El Chota is approximately $40 \mathrm{~km}$ from potato production in the village of San Gabriel. Although Pallatanga and Alchichipa are not principal potato-production zones, some potatoes are grown in these areas, and on two separate occasions, potato and tomato isolates were collected near these villages on the same day (Table 1). For potato and tomato isolates collected after 1993, a strict sampling scheme was not followed within collection sites, but isolates were taken from different fields when possible (Table 1). Some tomato isolates (fewer than five) were taken from infected fruits, but the exact number was not recorded.

Isolation and maintenance of the pathogen. $P$. infestans was isolated from potato leaves as described previously (7). P. infestans from tomato grew poorly on tuber slices and was therefore isolated by placing $1-\mathrm{cm}^{2}$ pieces of infected tissue on rye $\mathrm{B}$ agar (5) amended with antibiotics (vancomycin, $100 \mathrm{mg} / \mathrm{liter}$; polymixin B, $500 \mathrm{mg} / \mathrm{liter}$; ampicillin, $200 \mathrm{mg} / \mathrm{liter}$; and rifam-

TABLE 1. Number of isolates of Phytophthora infestans collected from potato and tomato at different locations in Ecuador between 1993 and 1996

\begin{tabular}{|c|c|c|c|c|}
\hline \multirow[b]{2}{*}{$\begin{array}{l}\text { Region in Ecuador } \\
\text { Location }^{\mathrm{a}}\end{array}$} & \multicolumn{2}{|c|}{ Potato } & \multirow{2}{*}{$\begin{array}{c}\text { Tomato } \\
\text { Nov. 1994- } \\
\text { Jan. } 1996\end{array}$} & \multirow[b]{2}{*}{ Total } \\
\hline & $\begin{array}{c}\text { Mar.-May } \\
1993^{\mathrm{b}}\end{array}$ & $\begin{array}{l}\text { Nov. 1994- } \\
\text { Feb. } 1995\end{array}$ & & \\
\hline \multicolumn{5}{|l|}{ Center } \\
\hline Riobamba & $10(10)$ & $4(?)$ & & 14 \\
\hline Pallatanga $^{c}$ & 1 & $14(14)$ & 15 & \\
\hline \multicolumn{5}{|l|}{ North center } \\
\hline Quito & $10(10)$ & $5(5)$ & $1(1)$ & 16 \\
\hline Alchichipa ${ }^{\mathrm{d}}$ & $6(1)$ & $17(5)$ & 23 & \\
\hline \multicolumn{5}{|l|}{ North } \\
\hline El Chota & & $28(23)$ & 28 & \\
\hline San Gabriel & $21(21)$ & $3(?)$ & & 24 \\
\hline Total & 41 & 19 & 60 & 120 \\
\hline
\end{tabular}

${ }^{a}$ The nearest city or town, except for El Chota, which is a valley in northern Ecuador.

${ }^{\mathrm{b}}$ Collection dates. Isolates collected during 1993 were part of an earlier study (7). The first number in each column is the number of isolates, and the number of fields sampled is in parentheses.

c On 25 November 1994, one isolate from potato and two from tomato were collected near the village of Pallatanga. The remaining 12 isolates from tomato were collected in Pallatanga during February 1995.

${ }^{d}$ Six isolates from potato and six from tomato were collected on 7 November 1995 in the village of Alchichipa. The remaining 11 tomato isolates were collected on the same day in the neighboring villages of Perucho and Puellaro. picin, $20 \mathrm{mg} / \mathrm{liter}$ ) and fungicides (pentachloronitrobenzene, $75 \% \mathrm{WP}, 67 \mathrm{mg} / \mathrm{liter}$; and benlate, $100 \mathrm{mg} / \mathrm{liter}$ ). This procedure worked only moderately well, and it was necessary to keep each isolate alive on tomato leaves until it was obtained in pure culture.

DNA fingerprinting. The RFLP fingerprints of 11 randomly selected isolates from tomato and 13 randomly selected isolates from potato collected after 1993 were analyzed with the moderately repetitive probe RG57 (11). Cultures were grown on pea broth at $18^{\circ} \mathrm{C}$ in the dark. After 10 days, the fungal tissue was harvested, frozen at $-80^{\circ} \mathrm{C}$ for several hours, and then lyophilized. Lyophilized tissue was ground in a microcentrifuge tube with a metal rod. DNA was extracted from the powdered mycelium as described previously (14). Gel electrophoresis, hybridization with ${ }^{32} \mathrm{P}$ random-primed probe RG57 (11), and autoradiography were all performed according to standard techniques (21). Techniques for RFLP fingerprinting of 1993 potato isolates were described previously (7).

Allozyme markers. Isolates were cultivated in a still culture of pea broth (12) or on rye B agar for 7 days at $18^{\circ} \mathrm{C}$. Mycelium grown on agar was harvested by scraping the agar surface with a scalpel. Protein was extracted from fresh mycelium as described by Goodwin et al. (10). Buffer systems, gel concentrations, current specifications, and staining procedures for electrophoretic analyses of glucose-6-phosphate isomerase ( $\mathrm{Gpi}$ ) and peptidase (Pep) were as previously described (10). Allozyme alleles are reported in migration distances relative to a commonly used control, which has arbitrarily been given a value of 100 .

Specific virulence. All isolates were tested on 11 potato differential plants, each containing one of 11 known major genes for resistance ( $\mathrm{R}$ genes $\mathrm{R} 1$ to $\mathrm{R} 11$ ), and on four tomato cultivars: FMX-93, New Yorker, Pieraline, and Pieralbo. Tomato differentials were supplied by G. W. Griffith (University of Wales, Bangor), and their major gene status was putatively considered to be as follows: FMX-93 and Pieralbo, free of major genes; New Yorker, Ph1; and Pieraline, Ph2 (G. W. Griffith, personal com-

TABLE 2. Genetic characterization of populations of Phytophthora infestans isolated from potato or tomato in Ecuador

\begin{tabular}{|c|c|c|}
\hline $\begin{array}{l}\text { Source } \\
\quad \text { Number of isolates }\end{array}$ & RFLP fingerprint ${ }^{\mathrm{a}}$ & $\begin{array}{r}\text { Clonal } \\
\text { lineage }^{\mathrm{b}}\end{array}$ \\
\hline \multicolumn{3}{|c|}{ Potato } \\
\hline \multicolumn{3}{|c|}{ Collected during $1993^{\mathrm{c}}$} \\
\hline 1 & $111110100 \underline{0001101000111011}$ & EC-1 \\
\hline 16 & $111110100 \underline{1001101000111011}$ & EC-1 \\
\hline 7 & Not tested & EC-1 \\
\hline \multicolumn{3}{|l|}{ Collected after 1993} \\
\hline 1 & $111110100 \underline{0001101000111011}$ & EC-1 \\
\hline 12 & 1111101001001101000111011 & EC-1* \\
\hline 23 & Not tested & EC-1 \\
\hline \multicolumn{3}{|l|}{ Tomato } \\
\hline $1^{\mathrm{d}}$ & Not tested & EC-1 \\
\hline 1 & $101110 \underline{00} \underline{0} 1001101000110011$ & US-1 \\
\hline 2 & $101110 \underline{1} 0 \overline{0} 1001101000110011$ & US-1 \\
\hline 8 & 1011101011001101000110011 & US-1* \\
\hline 48 & Not tested & US-1 \\
\hline \multicolumn{3}{|c|}{$\begin{array}{l}\text { a } R F L P=\text { restriction fragment length polymorphism. Underlined bands indi- } \\
\text { cate polymorphism within clonal lineages. }\end{array}$} \\
\hline \multirow{2}{*}{\multicolumn{3}{|c|}{$\begin{array}{l}\text { b Clonal lineage to which isolates belong on the basis of markers. All US-1 } \\
\text { isolates had mitochondrial haplotype IB, a Gpi banding pattern of } 86 / 100 \text {, }\end{array}$}} \\
\hline & & \\
\hline \multicolumn{3}{|c|}{ and a Pep banding pattern of $92 / 100$. All EC-1 isolates had mitochondrial } \\
\hline \multirow{2}{*}{\multicolumn{3}{|c|}{$\begin{array}{l}\text { haplotype IIA, a Gpi banding pattern of } 90 / 100 \text {, and a Pep banding pattern } \\
\text { of } 100 / 100 \text {. All isolates were A1 mating type. Isolates that do not have } \\
\text { RFLP fingerprints are identified on the basis of allozyme genotype, mating }\end{array}$}} \\
\hline \multirow{3}{*}{\multicolumn{3}{|c|}{$\begin{array}{l}\text { RFLP fingerprints are identified on the basis of allozyme genotype, mating } \\
\text { type, and mitochondrial haplotype. } *=\text { published RFLP and isozyme } \\
\text { genotypes that characterize that clonal lineage. }\end{array}$}} \\
\hline & & \\
\hline \multicolumn{2}{|c|}{ Isolates collected in an earlier study (7). } & \\
\hline & & \\
\hline
\end{tabular}


munication). Potato differentials were supplied by L. Turkensteen (IPO, Wageningen, Netherlands) and are currently maintained by the International Potato Center, Lima, Peru. The Peruvian potato cultivars Yungay and Chata Blanca were used as $\mathrm{R}$ gene-free controls.

Potato differentials were grown in a screenhouse where day length was extended to $16 \mathrm{~h}$ with halogen and incandescent lamps, because some of the differentials do not grow well under conditions of short days. Tomato differentials were grown in a glasshouse with $12 \mathrm{~h}$ of natural light per day. Inoculum preparation, inoculation, incubation, and scoring of specific virulence were all done as described previously (7).

Aggressiveness. The pathogenic aggressiveness of 17 isolates of $P$. infestans, 10 from tomato and seven from potato, was tested in two separate detached-leaf assays. Potato cultivars Uvilla, Bolona, and Yema de Huevo were used in the first assay and Chata Blanca, Cruza 148, and Yungay in the second. Tomato cultivars Flora Dade, FMX-93, and Pieralbo were used in the first assay and Flora Dade, FMX-93, and Heat in the second. Inoculum preparation was as described previously (7).

For both assays, fully expanded leaflets were chosen from plants between 6 weeks old and initiation of flowering grown as described above. Tomato leaves were sometimes used after flower initiation, but flower buds were removed. Leaflets were placed in petri dishes as previously described (7) and inoculated by placing one $10-\mu l$ drop of inoculum on each side of the midrib of each leaflet, thus producing two lesions per leaflet. Petri dishes were incubated at $15 \pm 2{ }^{\circ} \mathrm{C}$ with $14 \mathrm{~h}$ of fluorescent light per day. After 6 days of incubation, lesion diameter was measured with a ruler parallel to the leaflet midrib. Lesion growth was generally restricted by the width of the leaflet in the dimension perpendicular to the midrib, but lesion expansion continued parallel to the midrib throughout the duration of the assay.

Each host genotype-isolate combination was represented by eight lesions on four leaflets distributed randomly in two petri dishes. For the first assay, which included seven potato and seven tomato isolates, the interaction between isolate origin (potato or tomato) and inoculated host species (potato or tomato) was statistically tested in an analysis of variance. The experimental unit for this analysis was the average diameter of the four lesions in each petri dish. Therefore, there were two data values for each host genotype-isolate combination. Since these values are really subsamples of each combination, they were considered pseudoreplicates (17). The variance among pseudoreplicates was not used in tests of statistical significance. The model used for the analysis of variance was

$$
L D=u+a+b+a^{*} b+c(a)+d(b)+c^{*} d\left(a^{*} b\right)+e
$$

in which $L D=$ lesion diameter, $u=$ the overall mean, $a=$ origin of isolate (tomato or potato), $b=$ host species (tomato or potato), $c=$ isolate nested in origin, $d=$ plant nested in host species, and $e=$ the residual error. The interaction effect $c^{*} d\left(a^{*} b\right)$ was used as the denominator in the $F$ test of the interaction $a^{*} b$, which was the primary interest of this test.

The second aggressiveness assay was used to compare isolate 1916 from tomato with two other isolates from tomato and two isolates from potato. The objective of this assay was to determine whether the aggressiveness pattern of isolate 1916 was more like that of potato or tomato genotypes. Summary results are presented in tabular form.

Sensitivity to metalaxyl. Forty-three isolates from tomato and 59 from potato grown at $18^{\circ} \mathrm{C}$ in the dark on $10 \%$ V8 juice agar amended with 0,5 , and $100 \mu \mathrm{g}$ of metalaxyl per ml were assessed. On the basis of radial growth, sensitivity of the isolates was classified as susceptible (growth less than $40 \%$ of control with 5 and $100 \mu \mathrm{g}$ of metalaxyl per ml), intermediate (growth greater than or equal to $40 \%$ of control with $5 \mu \mathrm{g}$ of metalaxyl per ml but less than $40 \%$ of control with $100 \mu \mathrm{g} / \mathrm{ml}$ ), or resistant (growth $40 \%$ or more of control with $100 \mu \mathrm{g}$ of metalaxyl per $\mathrm{ml}$ ).

Mating type. Mating type was determined by pairing all test isolates with others of known A1 and A2 mating type on clarified rye A agar (5). The presence or absence of oospores was recorded after 15 days.

Mitochondrial haplotype. After DNA extraction (10), mitochondrial haplotype was determined by using primers and procedures developed and provided by G. W. Griffith. These primers identify four haplotypes: IA and IB, which represent "old" genotypes, as defined by Spielman et al. (25), and IIA and IIB, which represent "new" genotypes according to the same classification.

TABLE 3. Specific virulence patterns of Phytophthora infestans isolated from tomato or potato and inoculated on major-gene differential plants of both hosts

\begin{tabular}{|c|c|c|c|c|c|}
\hline \multicolumn{3}{|c|}{ Isolates collected from potato } & \multicolumn{3}{|c|}{ Isolates collected from tomato } \\
\hline Potato differentials ${ }^{\mathrm{a}}$ & Tomato differentials ${ }^{\mathrm{b}}$ & No. of isolates & Potato differentials ${ }^{\mathrm{a}}$ & Tomato differentials ${ }^{\mathrm{b}}$ & No. of isolates \\
\hline $0,1,3,4,7,8,10,11$ & 0,1 & 23 & $0,3,7$ & $0,1,2,3$ & 15 \\
\hline $0,1,3,4,7,8,10,11$ & $0,1,3$ & 11 & 0,3 & $0,1,2,3$ & 12 \\
\hline $0,1,3,4,7,10,11$ & 0,3 & 3 & $0,2,3$ & $0,1,2,3$ & 6 \\
\hline $0,1,2,3,4,6,7,10,11$ & 0,1 & 2 & NI & $0,1,2,3$ & 5 \\
\hline $0,1,2,3,4,6,7,8,10,11$ & 0,3 & 2 & 3 & $0,1,2,3$ & 3 \\
\hline $0,1,3,4,7,8,11$ & 0,3 & 1 & NI & $0,1,2$ & 1 \\
\hline $0,1,3,4,7,11$ & 0,1 & 1 & 0,4 & $0,1,2,3$ & 1 \\
\hline $0,1,3,4,7,10,11$ & 0 & 1 & 0,11 & $0,1,2,3$ & 1 \\
\hline $0,1,3,4,7,8,10,11$ & NI & 1 & $0,3,7$ & $0,1,2,3$ & 1 \\
\hline $0,1,3,4,6,7,10,11$ & 0,1 & 1 & $0,10,11$ & $0,1,3$ & 1 \\
\hline $0,1,2,3,4,6,7,10,11$ & $0,1,3$ & 1 & $0,1,3,7$ & $0,1,3$ & 1 \\
\hline
\end{tabular}

${ }^{a}$ Numbers represent major genes overcome by that pathotype. $\mathrm{NI}=$ no infection on any differential including those considered free of major genes. $*=$ isolate 1916 , which belongs to the EC-1 clonal lineage.

${ }^{\mathrm{b}}$ Numbers represent four tomato cultivars: $0=$ FMX-93, 1 = Pieralbo, 2 = New Yorker, and 3 = Pieraline. New Yorker has Ph1, and Pieraline has Ph2. FMX-93 and Pieralbo were considered free of $\mathrm{Ph}$ genes at the onset of the study. NI = no infection on any differential. 


\section{RESULTS}

Genetic description of $\boldsymbol{P}$. infestans in Ecuador. All potato isolates collected after 1993 had the dilocus allozyme genotype of the clonal lineage EC-1, as described previously (7) for isolates collected during 1993 (Table 2). EC-1 was shown to be the dominant clonal lineage on potato in Ecuador in 1993, and on the basis of our limited sample of 19 isolates, we conclude that no change has occurred. The Pep genotype 100/100 is characteristic of EC-1, but as in the earlier study (7), a few bands were unusually large. This may indicate the Pep 96/100 genotype, which is difficult to distinguish from the 100/100 genotype on potato starch gels. We prefer to describe all isolates as 100/100 until more precise electrophoretic techniques can be used to confirm the presence of the 96 allele in the EC-1 clonal lineage.

RFLP fingerprints of a subsample of 13 potato isolates collected after 1993 also corresponded to the EC-1 clonal lineage. In an earlier study (7), band 10 was missing in one of 17 isolates that were fingerprinted. We found that the same band was missing in one of 13 isolates that were fingerprinted. As in the earlier study, the one isolate for which band 10 was missing was identical to the

TABLE 4. Analysis of variance from the first detached-leaf assay for effects of origin (potato or tomato) of isolates of Phytophthora infestans and inoculated host species (potato or tomato) on diameter of lesions $(\mathrm{cm})$ in a detached-leaf inoculation assay

\begin{tabular}{lrrcc}
\hline Source & df & $\begin{array}{c}\text { Mean } \\
\text { square }\end{array}$ & $F$ value & $P>F$ \\
\hline Isolate origin $(\mathrm{O})$ & 1 & 8.25 & $\mathrm{NT}^{\mathrm{a}}$ & $\ldots$ \\
Host species $(\mathrm{H})^{\mathrm{b}}$ & 1 & 15.68 & $\mathrm{NT}$ & $\ldots$ \\
$\mathrm{O} * \mathrm{H}$ & 1 & 87.87 & 229.96 & 0.0001 \\
Isolate $\left.^{\mathrm{O}} \mathrm{O}\right)$ & 12 & 1.19 & 3.12 & 0.0022 \\
Plant $(\mathrm{H})$ & 3 & 5.39 & 14.13 & 0.0001 \\
Isolate $^{*}$ plant $\left.^{(\mathrm{O}}{ }^{*} \mathrm{H}\right)$ & 51 & 0.38 & $\mathrm{NT}$ & $\ldots$ \\
Residual error & 1,011 & 0.16 & $\ldots$ & $\ldots$ \\
\hline
\end{tabular}

${ }^{a}$ Not tested. Main effects of isolate origin and host species were not tested because of their highly significant interaction. This interaction, designated $\mathrm{O} * \mathrm{H}$, was tested by using the mean square for the interaction between individual isolates and plants, designated isolate * plant $(\mathrm{O} * \mathrm{H})$.

b The tomato cultivar Pieralbo was not used in this analysis because of apparent major gene interactions (see Table 5).

${ }^{c}$ Based on variance among petri dishes, which are pseudoreplications of the experiment. other EC-1 isolates for all other markers, and therefore we conclude that the missing band represents polymorphism that has arisen within the clonal lineage. All potato isolates were A1 mating type, also characteristic of the EC-1 clonal lineage (7), and had the IIA mitochondrial haplotype, which now serves as an additional genetic characteristic of the clonal lineage.

All isolates but one collected from tomato had the allozyme genotype 86/100 and 92/100 for Gpi and Pep, respectively, which is characteristic of the globally distributed clonal lineage US-1 (10). All tomato isolates with this dilocus allozyme genotype were IB mitochondrial haplotype and A1 mating type, also characteristic of US-1. Eight of the 11 tomato isolates that were fingerprinted in this study had the US-1 RFLP genotype (10). Two were similar but lacked band 9, and one isolate lacked both bands 9 and 7. Isolates lacking RFLP bands were identical to US-1 for other markers and are assumed to represent polymorphism that has developed within the clonal lineage. One isolate from tomato had the same allozyme genotype and mitochondrial haplotype as the EC-1 isolates from potato.

Specific virulence. The specific virulence patterns of potato and tomato populations of $P$. infestans differed greatly. Isolates were generally highly virulent on their respective host differentials but not on the alternative host differentials (Table 3). In several cases, isolates from one host did not infect any of the other host differentials, even those free of known major genes.

Two race-specific genes in tomato, $\mathrm{Ph} 1$ and $\mathrm{Ph} 2$, were reported previously $(16,20,29)$, but our data indicate that there is at least one additional race-specific gene in the four cultivars we used, although this gene was detectable only with EC-1 genotypes. Pieralbo, reportedly a major-gene-free isoline of the $\mathrm{Ph} 2$ differential Pieraline (19), should have behaved in a manner similar to that of FMX-93, also putatively free of major genes. However, some EC-1 isolates infected FMX-93 but not Pieralbo. The only tomato isolate that reacted this way was the one belonging to EC-1. All other tomato isolates (US-1) reacted equally to FMX-93 and Pieralbo (Table 3).

The one isolate from tomato belonging to EC-1 also reacted more like potato isolates in that it had an incompatible reaction on tomato cultivar New Yorker (Table 3). The universal incompatibility of potato isolates on New Yorker contrasted with a high degree of compatibility on this cultivar among tomato isolates. Only three of 59 US-1 isolates were incompatible on New Yorker.

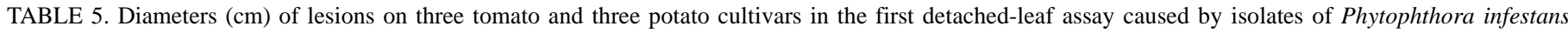
collected from tomato or potato in Ecuador

\begin{tabular}{|c|c|c|c|c|c|c|c|c|}
\hline \multirow{2}{*}{$\begin{array}{l}\text { Source } \\
\text { Isolate }^{\mathrm{a}}\end{array}$} & \multicolumn{4}{|c|}{ Tomato cultivars } & \multicolumn{4}{|c|}{ Potato cultivars } \\
\hline & Flora Dade & FMX-93 & Pieralbo & Mean & Uvilla & Bolona & Yema de Huevo & Mean \\
\hline \multicolumn{9}{|l|}{ Potato } \\
\hline 1361 & 1.61 & 2.26 & 0.33 & 1.94 & 2.19 & 2.90 & 1.71 & 2.27 \\
\hline 1561 & 1.35 & 1.54 & 0.00 & 1.45 & 3.06 & 2.87 & 2.54 & 2.82 \\
\hline 1654 & 1.32 & 1.85 & 0.44 & 1.59 & 3.26 & 3.33 & 2.43 & 3.01 \\
\hline 1961 & 2.36 & 3.00 & 0.76 & 2.68 & 2.89 & 4.25 & 2.14 & 3.09 \\
\hline 1988 & 2.28 & 2.53 & 1.44 & 2.41 & 3.58 & 3.84 & 2.94 & 3.45 \\
\hline 316 & 1.99 & 2.68 & 0.13 & 2.34 & 3.19 & 3.29 & 2.25 & 1.81 \\
\hline 920 & 1.68 & 2.13 & 0.00 & 1.91 & 3.38 & 3.58 & 2.88 & 3.28 \\
\hline Mean & 1.8 & 2.28 & 0.44 & 2.05 & 3.08 & 3.44 & 2.41 & 2.98 \\
\hline \multicolumn{9}{|l|}{ Tomato } \\
\hline 1618 & 2.53 & 3.45 & 1.93 & 2.44 & 0.63 & 0.51 & 0.08 & 0.41 \\
\hline 1627 & 3.29 & 3.46 & 3.29 & 3.35 & 2.16 & 1.61 & 1.66 & 1.81 \\
\hline 1642 & 2.38 & 2.58 & 2.73 & 2.56 & 1.46 & 1.72 & 1.46 & 1.55 \\
\hline 2515 & 3.63 & 4.31 & 3.56 & 3.83 & 1.06 & 1.81 & 0.81 & 1.23 \\
\hline 2542 & 2.80 & 4.45 & 4.13 & 3.79 & 1.50 & 1.43 & 0.46 & 1.13 \\
\hline 2548 & 3.68 & 3.89 & 3.68 & 3.75 & 1.38 & 1.45 & 0.23 & 1.02 \\
\hline 2563 & 4.03 & 4.65 & 4.00 & 4.23 & 1.81 & 1.48 & 0.39 & 1.23 \\
\hline Mean & 3.19 & 3.83 & 3.33 & 3.45 & 1.43 & 1.43 & 0.73 & 1.19 \\
\hline
\end{tabular}

a Isolate code of the CIP collection of P. infestans in Quito, Ecuador. 
No clear relationship among tomato and potato avirulence genes in $P$. infestans could be deduced from our results. Isolates that were avirulent on all potato differentials were virulent on some or even all tomato differentials (Table 3 ). Therefore, all avirulence genes for tomato expressed in this study appear to be independent of avirulence genes that interact with known potato $\mathrm{R}$ genes. None of the isolates from tomato or potato infected the potato differential for R5.

Pathogenic aggressiveness. In the first assay, we found a very clear pattern of pathogenic aggressiveness; isolates caused larger lesions on their respective host than on their alternative host. This resulted in a statistically significant interaction between origin of isolate (tomato or potato) and host (Table 4), which was clearly visible when mean lesion diameter values were examined (see row and column means in Table 5).

The general interaction measured in the analysis of variance (Table 4) was true for virtually all isolate $\times$ cultivar interactions (Table 5). There were no cases in which isolates were highly aggressive on their alternative host. However, tomato isolate 1642 was weakly aggressive on all tomato cultivars, and in a couple of cases, potato isolates caused lesions on tomato as large as those caused by isolate 1642 . Some potato isolates were virulent on tomato cultivar Pieralbo (Table 5), so this cultivar was eliminated from the analysis of variance (Table 4).

In the second assay, isolate 1916 (EC-1), which was collected from tomato, was more aggressive on potato than on tomato and less aggressive on tomato than the US-1 isolates (Table 6). Isolates from potato caused lesions about twice as long on their host as on their alternative host. Isolates from tomato caused lesions about 2.7 times as long on their host as on their alternative host. This was caused, in part, by the lack of infection by tomato isolates on potato cultivar Cruza 148, which is highly resistant to $P$. infestans in the field. Since none of the tomato isolates infected Cruza 148, it is not known whether this represents a very high level of quantitative resistance or the response of this cultivar to a previously unidentified avirulence allele in these tomato isolates.

In the second assay, we examined symptoms and noticed that EC-1 genotypes (including 1916) caused deep brown necrosis in all three tomato cultivars and sporulation occurred only on necrotic areas. In contrast, lesions caused by US-1 genotypes had no distinct margins, and sporulation was profuse on green tissue. Determining the limits of sporulation, which was used in determining lesion diameter, sometimes required examination with a stereoscope.

Sensitivity to metalaxyl. There was a marked and statistically significant difference in the three levels of sensitivity to metalaxyl between tomato and potato isolates (Table 7). More than half the isolates tested from potato (30 of 59) were resistant to metalaxyl, but only three of 43 isolates from tomato were classified as resis- tant. In contrast, only five of 59 isolates from potato were intermediately resistant, while 23 of 43 from tomato were intermediate. In general, isolates from potato are more resistant than isolates from tomato. We do not have fungicide-usage data for the two crops to compare with these results.

\section{DISCUSSION}

All our data, with the exception of those for one isolate discussed below, indicate that the two populations of $P$. infestans attacking potato and tomato in Ecuador are different. All isolates collected from potato for this study belong to the EC-1 clonal lineage as described previously (7). All but one of 60 isolates from tomato belong to the globally distributed US-1 clonal lineage (10). The one variant had the same dilocus allozyme genotype as EC-1 and a virulence pattern similar to that of other EC-1 isolates, and therefore we assume that it belongs to that clonal lineage.

An earlier study in Ecuador indicated that a small percentage of isolates collected between 1990 and 1993 from potato were US-1 (7). We believe that this earlier finding is not inconsistent with the hypothesis of host specificity for the following reasons. The authors in the earlier study hypothesized that EC-1 had been introduced into Ecuador within the last two decades and that it was replacing US-1 on potato. Therefore, they considered EC-1 to have greater fitness than US-1 on potato. They also hypothesized that prior to the introduction of EC-1, US-1 had been the dominant clonal lineage on potato in Ecuador. This theory was based on an analysis of specific virulence done during the 1970s in Ecuador (1) and on other studies that demonstrated that US-1 was dominant on potato in Peru during the 1980s $(10,28)$. The present study demonstrates that while EC-1 is replacing US-1 on potato, it is not replacing US-1 on tomato. Whether host specificity existed within the US-1 clonal lineage before the introduction of EC-1 remains unclear.

The situation in Ecuador is similar to that in Brazil, where US-1 (A1 mating type) has been found exclusively on tomato (10) and an A2 genotype exclusively on potato (4). At the time that sampling was done in Brazil, there was no evidence for recombination between the two mating types (4). On the basis of a limited sample from the area of Rionegro near Medellin, Colombia, we

TABLE 7. Level of sensitivity to metalaxyl of isolates of Phytophthora infestans from potato and tomato in Ecuador ${ }^{\mathrm{a}}$

\begin{tabular}{lccc}
\hline & \multicolumn{3}{c}{ Sensitivity level } \\
\cline { 2 - 4 } Origin of isolates & Susceptible & Intermediate & Resistant \\
\hline Potato & 24 & 5 & 30 \\
Tomato & 17 & 23 & 3 \\
\hline
\end{tabular}

${ }^{a}$ Chi-square value for independence $=28.81 ; P=0.001 ;$ and $\mathrm{df}=2$.

TABLE 6. Diameters $(\mathrm{cm})$ of lesions caused by EC-1 genotype 1916 of Phytophthora infestans collected from tomato and two other EC-1 genotypes from potato and two US-1 genotypes from tomato

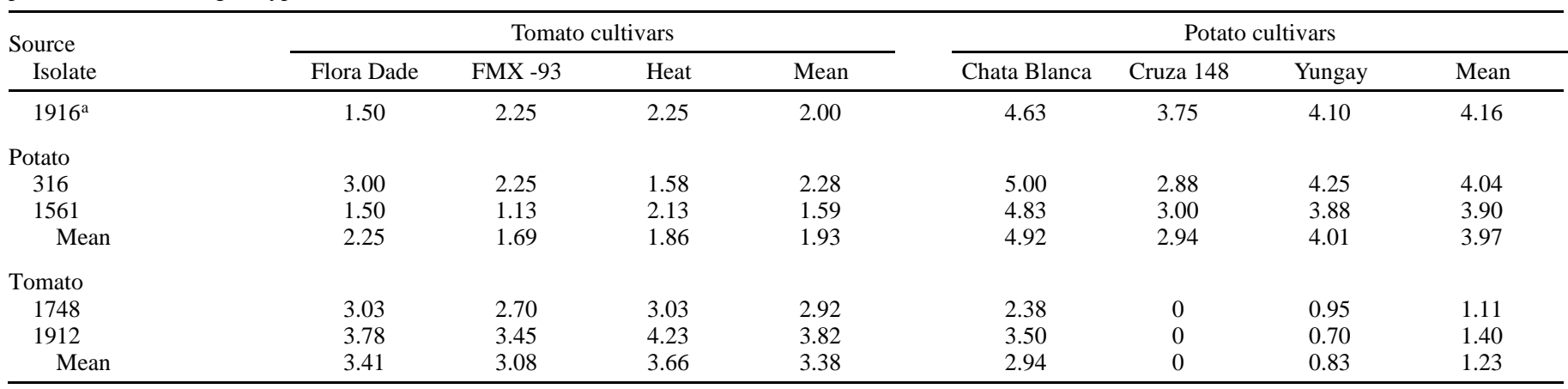

${ }^{a}$ Isolate 1916 is EC-1 like potato isolates but was collected from tomato. 
have also determined that EC-1 is primarily associated with potato and US-1 with tomato in that country (G. Forbes, unpublished data).

In contrast to our results, a recent study found that some genotypes in North America are equally aggressive on potato and tomato (20). We found no isolates that were highly aggressive on both hosts. Furthermore, the fact that separate genotypes have been found in association with both hosts in several parts of the world would seem to argue against the presence of dually aggressive genotypes in these regions. Dually aggressive genotypes could be particularly destructive in developing countries where both tomato and potato are grown year round in the same geographic regions. Many such areas currently exist in the highland tropics of Africa, Asia, and South America.

Host specificity has important implications for disease management. If the same population of the pathogen attacks both hosts, then farmers, extension workers, and researchers who were formerly concerned with only one host now need to coordinate efforts. Our data suggest that this situation has not yet occurred in Ecuador nor in several other parts of South America, as discussed above.

Isolate 1916, the one EC-1 isolate collected from tomato, probably represents a weakly pathogenic isolate found by chance. This hypothesis is supported principally by three observations: (i) no other EC-1 isolates were collected from tomato in any part of Ecuador; (ii) three other isolates collected from the same field were US-1; and (iii) isolate 1916 was more aggressive on potato than on tomato and less aggressive on tomato than US-1 genotypes in a detached-leaf test (Table 6). Nonetheless, populations of $P$. infestans on potato and tomato should be monitored in the future for the presence of genotypes that attack both hosts with equal aggressiveness.

In countries such as Ecuador where US-1 is found principally on tomato, changes in the genetic structure of the pathogen population may be effectively and efficiently detected with a simple assay for Gpi genotype. The Gpi 86/100 genotype is rare outside Mexico, except in the US-1 clonal lineage $(10,25)$. The $86 / 100$ banding pattern can be detected from field-collected lesions by using a cellulose acetate assay, which takes less than $1 \mathrm{~h}$ (13). Therefore, a large number of isolates can be rapidly screened for the presence (tomato) or absence (potato) of the 86/100 genotype. Only deviations from expected patterns would need be assessed with more expensive and laborious markers.

The second objective of our study was to elucidate the role of specific virulence in host specificity. Our data suggest that specific virulence is not a primary causal factor but may be related to host specificity and should be considered in future research directed at this problem. We found, for example, that potato isolates did not infect the tomato cultivar New Yorker, which carries major gene Ph1 (Table 3), while most tomato isolates did infect New Yorker. Solely on the basis of this virulence test, the existence of an avirulence gene for $\mathrm{Ph} 1$, which is costly for the pathogen to lose, would be a simple explanation for the fact that pathogenic aggressiveness on tomato has not yet evolved within EC-1. Nonetheless, the role of $\mathrm{Ph} 1$ as the sole determinant of host specificity is not supported by all of our data nor by circumstantial evidence.

For example, if $\mathrm{Ph} 1$ were the main determinant of host specificity in Ecuador, we would expect to find it in all or most tomato cultivars in Ecuador. In fact, $\mathrm{Ph} 1$ is uncommon in commercial tomato cultivars (H. Judelson and L. Black, personal communication) and therefore is probably not present in most of the tomato cultivars we sampled. Furthermore, avirulence to Ph1 does not appear to be a common feature of potato isolates. Many potato isolates in North America do infect Ph1 (16). It is not known, however, whether these isolates are among those that are equally aggressive on both potato and tomato.

Our study also leads to another observation regarding specific virulence. Apparently, P. infestans has different avirulence genes for potato and tomato, at least among those that can be identified with existing differential cultivars of both hosts. We found that several isolates that possess all known avirulence genes for potato infected all four tomato differentials (Table 3). Apparently, avirulence genes for potato do not elicit a hypersensitive response in tomato. Similarly, several isolates that did not infect any tomato differentials were highly virulent on potato (Table 3 ). Our hypothesis is supported by another study (26), which found that virulence to $\mathrm{Ph} 1$ was independent of virulence to potato genes R1 to R4.

None of the isolates tested infected potato differential R5. In an earlier study (7), in which the same set of differential plants was used, virulence on R5 was found in two of 108 isolates tested, indicating that virulence for this major gene does exist in Ecuador at a low frequency.

In contrast to specific virulence, pathogenic aggressiveness appears to explain the host specificity we encountered in Ecuador. All isolates of $P$. infestans tested in the two detached-leaf assays infected both hosts, but infection was always more severe on the original host. The hypothesis that quantitative aggressiveness determines host specificity is consistent with earlier studies $(2,29)$ and explains why genotypes of $P$. infestans may be found on their alternative hosts in nature.

\section{ACKNOWLEDGMENTS}

This research was supported in part by the Program in Science and Technology Cooperation, Office of the Science Advisor, U.S. Agency for International Development, Project 12.141.

\section{LITERATURE CITED}

1. Anonymous. 1976. Informe Anual de Actividades. Departamento de Fitopatologia, Instituto Nacional de Investigaciones Agropecuarias, Quito, Ecuador.

2. Berg, A. 1926. Tomato late blight and its relation to late blight of potato. W. Va. Agric. Exp. Stn. Bull. 205.

3. Black, W., Mastenbroek, C., Mills, W. R., and Peterson, L. C. 1953. A proposal for an international nomenclature of races of Phytophthora infestans and of genes controlling immunity in Solanum demissum derivatives. Euphytica 2:173-178.

4. Brommonschenkel, S. H. 1988. Pathogenicity, compatibility, cytogenetics and isoenzyme patterns of Brazilian isolates of Phytophthora infestans (Mont.) de Bary. M.S. thesis. Universidade Federal de Viçosa, Viçosa, Brazil.

5. Caten, C. E., and Jinks, J. L. 1968. Spontaneous variability of single isolates of Phytophthora infestans. I. Cultural variation. Can. J. Bot. 46: 329-348.

6. Clinton, G. P. 1903. Notes on parasitic fungi. Page 365 in: Rep. Conn. Agric. Exp. Stn. 1903.

7. Forbes, G. A., Escobar, X. C., Ayala, C. C., Revelo, J., Ordoñez, M. E., Fry, B. A., Doucett, K., and Fry, W. E. 1997. Population genetic structure of Phytophthora infestans in Ecuador. Phytopathology 87:375-380.

8. Fry, W. E., Drenth, A., Spielman, L. J., Mantel, B. C., Davidse, L. C., and Goodwin, S. B. 1991. Population genetic structure of Phytophthora infestans in the Netherlands. Phytopathology 81:1330-1336.

9. Giddings, N. J., and Berg, A. 1919. A comparison of the late blights of tomato and potato. Phytopathology 9:209-211.

10. Goodwin, S. B., Cohen, B. A., and Fry, W. E. 1994. Panglobal distribution of a single clonal lineage of the Irish potato famine fungus. Proc. Natl. Acad. Sci. USA 91:11591-11595.

11. Goodwin, S. B., Drenth, A., and Fry, W. E. 1992. Cloning and genetic analyses of two highly polymorphic, moderately repetitive nuclear DNAs from Phytophthora infestans. Curr. Genet. 22:107-115.

12. Goodwin, S. B., and Fry, W. E. 1994. Continued migration of A2 mating type, metalaxyl-resistant genotypes of Phytophthora infestans in the eastern United States and Canada. (Abstr.) Phytopathology 84:1371.

13. Goodwin, S. B., Schneider, R. E., and Fry, W. E. 1995. Use of celluloseacetate electrophoresis for rapid identification of allozyme genotypes of Phytophthora infestans. Plant Dis. 79:1181-1185.

14. Goodwin, S. B., Spielman, L. J., Matuszak, J. M., Bergeron, S. N., and Fry, W. E. 1992. Clonal diversity and genetic differentiation of Phytophthora infestans populations in northern and central Mexico. Phytopathology 82:955-961.

15. Goodwin, S. B., Sujkowski, L. S., Dyer, A. T., Fry, B. A., and Fry, W. E. 1995. Direct detection of gene flow and probable sexual reproduction of 
Phytophthora infestans in northern North America. Phytopathology 85: 473-479.

16. Goodwin, S. B., Sujkowski, L. S., and Fry, W. E. 1995. Rapid evolution of pathogenicity within clonal lineages of the potato late blight disease fungus. Phytopathology 85:669-676.

17. Hurlbert, S. H. 1984. Pseudoreplication and the design of ecological field experiments. Ecol. Monogr. 54:187-211.

18. Koh, Y. J., Goodwin, S. B., Dyer, A. T., Cohen, B. A., Ogoshi, A., Sato, N., and Fry, W. E. 1994. Migrations and displacements of Phytophthora infestans populations in east Asian countries. Phytopathology 84:922927.

19. Latterot, H. 1975. Séléction pour la resistance ou mildiou, Phytophthora infestans Mont. de Bary chez la tomate. Ann. Amelior. Plant. 25:129149.

20. Legard, D. E., Lee, T. Y., and Fry, W. E. 1995. Pathogenic specialization in Phytophthora infestans: Aggressiveness on tomato. Phytopathology 85:1356-1361.

21. Maniatis, T. A., Fritsch, J. F., and Sambrook, J. 1982. Molecular Cloning: A Laboratory Manual. Cold Spring Harbor Laboratory, Cold Spring Harbor, NY.

22. Payen, M. 1847. Végétation du Botrytis infestans a l'intérieur de fruits du Solanum lycopersicon, erythrocarpum (tomate). C. R. Acad. Sci. (Paris) 25:521-524.

23. Small, T. 1932. The relation between potato blight and tomato blight.
Ann. Appl. Biol. 25:271-275.

24. Smith, R. E. 1906. Tomato diseases in California. Calif. Agric. Exp. Stn. Bull. 175.

25. Spielman, L. J., Drenth, A., Davidse, L. C., Sujkowski, L. J., Gu, W., Tooley, P. W., and Fry, W. E. 1991. A second world-wide migration and population displacement of Phytophthora infestans? Plant Pathol. 40: 422-430.

26. Spielman, L. J., McMaster, B. J., and Fry, W. E. 1989. Dominance and recessiveness at loci for virulence against potato and tomato in Phytophthora infestans. Theor. Appl. Genet. 77:832-838.

27. Thaxter, S. P. 1891. Diseases of tomatoes. Pages 95-96: Rep. Conn. Agric. Exp. Stn. 1893.

28. Tooley, P. W., Therrien, C. D., and Ritch, D. L. 1989. Mating type, race composition, nuclear DNA content, and isozyme analysis of Peruvian isolates of Phytophthora infestans. Phytopathology 79:478-481.

29. Turkensteen, L. J. 1973. Partial resistance of tomatoes against Phytophthora infestans, the late blight fungus. Ph.D. thesis. Wageningen Agricultural University, Wageningen, the Netherlands.

30. Vartanian, V. G., and Endo, R. M. 1985. Overwintering hosts, compatibility types, and races of Phytophthora infestans on tomato in southern California. Plant Dis. 69:516-519.

31. Wiltshire, S. P. 1913. A note on Phytophthora infestans occurring on tomatoes. Pages $92-93$ in: Rep. Agric. Hortic. Res. Stn. Univ. Bristol 1915. 